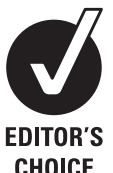

CHOICE
${ }^{1}$ CSIR-Building and Road Research Institute, Kumasi, Ghana

${ }^{2}$ Department of Community Health, Kwame Nkrumah University of Science and Technology, Kumasi, Ghana ${ }^{3}$ Department of Surgery, Kwame Nkrumah University of Science and Technology, Kumasi, Ghana

${ }^{4}$ Graphic Communications Group, Kumasi, Ghana

${ }^{5}$ Department of Surgery, Harborview Injury Prevention and Research Center, University of Washington, Seattle, Washington, USA

${ }^{6}$ Department of Pediatrics, Harborview Injury Prevention and Research Center, University of Washington, Seattle, Washington, USA ${ }^{7}$ Department of Pediatrics, Seattle Children's Hospital Seattle, Washington, USA

\section{Correspondence to}

Isaac Kofi Yankson, PO Box AH8424, Kumasi, Ghana; kofi.yankson@gmail.com

Accepted 28 December 2009

\title{
Reporting on road traffic injury: content analysis of injuries and prevention opportunities in Ghanaian newspapers
}

\author{
Isaac Kofi Yankson, ${ }^{1}$ Edmund N L Browne, ${ }^{2}$ H Tagbor, ${ }^{2}$ Peter Donkor, ${ }^{3}$ \\ Robert Quansah, ${ }^{3}$ George Ernest Asare, ${ }^{4}$ Charles N Mock, ${ }^{5}$ Beth E Ebel ${ }^{6,7}$
}

\section{ABSTRACT}

In order to analyse traffic injury reporting in Ghanaian newspapers and identify opportunities for improving road safety, the content of 240 articles on road traffic injury was reviewed from 2005 to 2006 editions of two stateowned and two privately owned newspapers. The articles comprised reports on vehicle crashes (37\%), commentaries (33\%), informational pieces (12\%), reports on pedestrian injury (10\%), and editorials $(8 \%)$. There was little coverage of pedestrian injuries, which account for half of the traffic fatalities in Ghana, but only $22 \%$ of newspaper reports. Only two articles reported on seatbelt use. Reporting patterns were similar between public and private papers, but private papers more commonly recommended government action $(50 \%)$ than did public papers $(32 \%, p=0.006)$. It is concluded that Ghanaian papers provide detailed coverage of traffic injury. Areas for improvement include pedestrian injury and attention to preventable risk factors such as road risk factors, seatbelt use, speed control, and alcohol use.

\section{INTRODUCTION}

In developing countries, motorisation has been accompanied by rapid growth in road traffic injuries, which have become a leading cause of death and disability. According to the World Health Organization, in 2002 an estimated 1.2 million people died and 50 million were injured or disabled in traffic crashes worldwide, costing the global community US\$518 billion. The majority of these deaths $(90 \%)$ occur in developing countries, where road safety measures have not been adequately implemented. ${ }^{1}$

Public perceptions about road safety are influenced by the amount and type of coverage they receive in the popular press. Press coverage of crashes has the potential to shape readers' perceptions of personal risk and their beliefs about the nature and preventability of crashes through the frames they employ, including the choice of which stories to cover, choice of detail, and the context in which information is conveyed. ${ }^{4}$

We conducted the current study to analyse the content of road traffic injury reporting in the Ghanaian papers and identify opportunities to effectively promote injury prevention. We also wished to explore the relationship between newspaper ownership models and reporting content, given the prominence of state-owed newspapers in many developing countries.

\section{METHODS}

Setting

This study was conducted in Ghana, a West African country of 22 million people with GNP of US $\$ 590$ per capita in 2007.5 Vehicle use has grown steadily during the past 15 years, accompanied by higher rates of road traffic crashes, injuries, and deaths.

\section{Study design}

Content analysis of Ghanaian newspaper articles.

\section{Article inclusion}

The study included newspaper articles on road traffic injury published in the Graphic and Times (publicly owned) and the Guide and Chronicle (privately owned) from 1 January 2005 to 31 December 2006. The only two government-owned daily newspapers were chosen. Of over 35 private newspapers, two daily papers were randomly selected. All four selected are daily newspapers with national distribution. According to marketing offices, the Graphic circulates 100000; Times, 35 000; Guide, 45 000; and Chronicle, 30000 newspapers daily. We selected a minimum of 50 articles from each paper. For the Graphic, we reviewed all 68 articles on road traffic crashes identified in 2005. For the other three papers, we reviewed every article on road traffic crashes identified in 2005-06. Key variables were abstracted and classified for each article (table 1)

\section{Data analysis}

Data were entered and analysed using EpiInfo 3.2 (CDC, 2004). Comparisons in reporting patterns were evaluated using $\chi^{2}$ and Fisher's exact test as appropriate.

\section{Reliability}

Article content was evaluated by one author (IKY) and $10 \%$ of the articles were re-evaluated by a second observer (GEA) who was unaware of the first observer's ratings. Inter-rater reliability for main study variables was high: cause of injury (agreement 88\%, $\kappa 0.75, \mathrm{p}=0.001$ ); government specific actions (agreement 96\%, $\kappa 0.88, \mathrm{p}<0.001$ ); public specific actions (agreement $88 \%, \kappa 0.75$, $\mathrm{p}=0.001$ ).

\section{Human subjects approval}

The study used publicly available information and was considered exempt from review by the University of Washington Human Subjects Division. 
Table 1 Descriptive data for newspaper articles on road traffic crashes

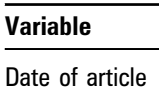

Type of article

Type of crash

Number of vehicles involved

Number of on-the-spot or prehospital

deaths

Number of people injured

How the victims were transported to a health facility

Potential causes of the crash or the resultant injury

Public specific action

Government specific action

Follow-up publication

Categories or description of variable

Commentary: General article on road traffic crashes, often written by the general public Editorial: Piece by editor, often expressing a viewpoint

Informational piece: Report on data released by police, National Road Safety Commission, or other source

Report on crash: Article reporting on a specific motor vehicle crash event Report on pedestrian injury: Article reporting on specific incidents in which a pedestrian was killed, injured, or hit by a vehicle Head-on, rear-on, side swipe, right angled, overturn, hit object, hit parked/broken down vehicle, or hit pedestrian

Examples: use of alcohol, speeding, vehicle maintenance, non-use of seatbelts and crash helmets

Actions that individuals and/or civil society groups could/should take to prevent crashes or related injuries in the future

Actions the central government or agencies could/should take to prevent future crashes or related injuries

Article written in reference to a prior article on a crash, typically following up on the fate of those involved

\section{RESULTS}

\section{Types of articles}

We reviewed 240 articles on road traffic injury. These articles were categorised in mutually exclusive groups as follows (table 2): crash report (38\%), commentary (33\%), editorial (7.5\%), informational piece $(12 \%)$, and pedestrian injury report $(10 \%)$.

\section{Details of crashes reported}

There were four times as many motor vehicle crashes reported as pedestrian injuries. Most press articles (70\%) reported on number of persons injured, and nearly every article indicated whether fatal injuries occurred (92\%). Articles rarely stated how victims were transported to a health facility (9.6\%). Few articles $(11 \%)$ provided follow-up information on crash victims.

\section{Contributing factors}

Potential contributing factors were generally reported, especially in commentaries and editorials (table 3 ). Contributing factors were less frequently reported for pedestrian injuries (56\%) than for all other types of articles (78\%, $\mathrm{p}=0.02)$ and for motor vehicle crashes specifically $(76 \%, \mathrm{p}=0.06)$. Papers reported contributing factors including excessive speeding (34\%), alcoholimpaired driving (13\%), wrongful overtaking (12\%), overloaded vehicle $(6.6 \%)$, and driver fatigue $(1.7 \%)$. None mentioned posted speed limits or poor road design. Protective factors were rarely mentioned. Only two articles (0.8\%) reported seatbelt use and only one article $(0.4 \%)$ offered a commentary on the protective role of seatbelts. There was little mention of other protective factors: divided roads, sidewalks, or securing vehicle loads.

\section{Recommendations for road safety action}

We evaluated articles for two types of recommended actions: public specific actions (PSAs) and government specific actions (GSAs) (table 1). PSAs were frequently recommended in commentaries, editorials, and informational pieces (table 4). Reports on crashes and pedestrian injuries were far less likely to contain PSAs. Commentaries in public papers were more likely $(85 \%)$ than those in private papers $(63 \%)$ to recommend PSAs $(\mathrm{p}=0.03)$.

The most frequently cited PSAs were: (i) advocating a stronger role for civil society, for example inspecting drivers' licences (mentioned in $17 \%$ of articles that recommended a PSA); (ii) drivers' unions taking actions directed at poor drivers (10\%); (iii) reduction in risky driving practices (drunk driving, fatigue driving, excessive speeding, and wrongful overtaking) (8.8\%); (iv) driver self-restraint (7.8\%); (v) pedestrian caution $(7.8 \%)$; (vi) vehicle maintenance (6.7\%); (vii) driver education $(5.9 \%)$; and (viii) safe road use practices (seatbelt use, defensive driving) (4.9\%). Few articles mentioned PSAs to limit speed $(5.9 \%)$ or use of alcohol $(2.9 \%)$.

GSAs were more frequently described in commentaries, editorials, and informational pieces (table 4). Private papers were more likely to recommend a GSA (50\%) than were public papers $(32 \%, p=0.006)$. Frequently cited GSAs were: (i) traffic law enforcement (speeding, vehicle overloading, or prosecution of offending drivers, 32\%); (ii) education of drivers, pedestrians, or riders by the police) (15\%); (iii) policy formulation and enactment of laws (11\%); (iv) use of radar guns, breathalysers, security cameras at traffic lights, or establishment of call centres on highways (9\%); (v) road improvements such as road marking, lighting, signage, or maintenance (7\%); and (vi) pre-hospital emergency services or first aid training (6\%). Only $9.3 \%$ of articles mentioned speed and $7.5 \%$ mentioned alcohol.

\section{DISCUSSION}

This study sought to identify patterns of reporting on road traffic injuries in Ghana. Injury was widely reported, often with recommendations for private sector and public sector actions There were several areas in which reporting could be strengthened. In Ghana, as in many other developing countries, pedestrian injuries are the most common road traffic death, accounting for $43 \%$ of deaths in $2007 .{ }^{67}$ Yet articles on vehicle

Table 2 Frequency of injury article types

\begin{tabular}{|c|c|c|c|c|c|c|}
\hline Source & Crash report & Pedestrian report & Commentary & Editorial & Informational piece & Total \\
\hline \multicolumn{7}{|c|}{ Public newspapers } \\
\hline Graphic & $35(51 \%)$ & $7(10 \%)$ & $15(22 \%)$ & $2(3 \%)$ & $9(13 \%)$ & $68(100 \%)$ \\
\hline Times & $16(27 \%)$ & $9(15 \%)$ & $24(41 \%)$ & $4(7 \%)$ & $6(10 \%)$ & $59(100 \%)$ \\
\hline \multicolumn{7}{|c|}{ Private newspapers } \\
\hline Guide & $33(54 \%)$ & $5(8 \%)$ & $13(21 \%)$ & $4(7 \%)$ & $6(10 \%)$ & $61(100 \%)$ \\
\hline Chronicle & $6(12 \%)$ & $4(8 \%)$ & $27(52 \%)$ & $8(15 \%)$ & $7(13 \%)$ & $52(100 \%)$ \\
\hline Total & $90(38 \%)$ & $25(10 \%)$ & $79(33 \%)$ & $18(8 \%)$ & $28(12 \%)$ & $240(100 \%)$ \\
\hline
\end{tabular}


Table 3 Percentage of articles mentioning contributing factors for road traffic injury*

\begin{tabular}{lllllll}
\hline Source & Commentary & Editorial $\dagger$ & Informational piece & Crash report & Pedestrian report & Total \\
\hline Public & $80 \%(31 / 39)$ & $50 \%(3 / 6)$ & $73 \%(11 / 15)$ & $77 \%(39 / 51)$ & $44 \%(7 / 16)$ & $72 \%(91 / 127)$ \\
Private & $83 \%(33 / 40)$ & $100 \%(12 / 12)$ & $69 \%(9 / 13)$ & $74 \%(29 / 39)$ & $78 \%(7 / 9)$ & $80 \%(90 / 113)$ \\
Total & $81 \%(64 / 79)$ & $83 \%(15 / 18)$ & $71 \%(20 / 28)$ & $76 \%(68 / 90)$ & $56 \%(14 / 25)$ & $75 \%(181 / 240)$ \\
\hline
\end{tabular}

*Percentages given in table, with numerator and denominator in parentheses.

$t p=0.025$ for differences between public and private.

Table 4 Percentage of article types recommending a public specific action and government specific action $\dagger$

\begin{tabular}{|c|c|c|c|c|c|c|}
\hline Source & Commentary & Editorial & $\begin{array}{l}\text { Informational } \\
\text { piece }\end{array}$ & $\begin{array}{l}\text { Crash } \\
\text { report }\end{array}$ & $\begin{array}{l}\text { Pedestrian } \\
\text { report }\end{array}$ & Total \\
\hline Public & $85 \%(33 / 39)$ & $33 \%(2 / 6)$ & $87 \%(13 / 15)$ & $10 \%(5 / 51)$ & $13 \%(2 / 16)$ & $43 \%(55 / 127)$ \\
\hline Total & $73 \%(58 / 79)^{*}$ & $61 \%(11 / 18) \ddagger$ & $71 \%(20 / 28) \neq$ & $10 \%(9 / 90)$ & $16 \%(4 / 25)$ & $43 \%(102 / 240)$ \\
\hline \multicolumn{7}{|c|}{ Government specific action } \\
\hline Public & $69 \%(27 / 39)$ & $67 \%(4 / 6)$ & $53 \%(8 / 15)$ & $2.0 \%(1 / 51)$ & $6.3 \%(1 / 16)$ & $32 \%(41 / 127)$ \\
\hline
\end{tabular}

${ }^{*} \mathrm{p}<0.05$.

†Percentages given in table, with numerator and denominator in parentheses.

$\neq \mathrm{p}<0.10$ for differences between public and private.

crashes outnumbered reports on pedestrian injuries by 3 to 1 , with few suggestions for preventive actions.

Preventive steps were discussed in commentaries and editorials, but low coverage in crash reports represents a missed opportunity to link crash consequences with injury prevention. Commentaries were often written by the general public, some of whom are proficient in road safety. Editorials and informational pieces were usually written by editorial staff or national experts, often with experience covering public policy. Reports on crashes and pedestrian injuries were more commonly written by on-the-ground reporters, with little formal background in injury prevention.

Finally, greater emphasis should be placed on known, effective prevention strategies. Less than $1 \%$ of articles mentioned restraint use and only one article offered a commentary on the role of seatbelts in protecting occupants. Approximately $90 \%$ of pedestrians survive impacts with cars at speeds up to $30 \mathrm{~km} / \mathrm{h}$, but more than $50 \%$ will die at speeds of $45 \mathrm{~km} / \mathrm{h}$ or more. ${ }^{1}$ Speed was often indicated as a contributing factor, but few articles discussed strategies to control speeding, such as enforcement and traffic calming. Similar considerations pertain to other major risk factors, including drunk driving and driver fatigue.

Previous work has considered the potential use of newspaper reports for injury surveillance in developed and developing countries. $^{2}$ To our knowledge, this is the first article to examine the press's role in injury prevention in a developing country. This study showed similarities to previous literature from highincome countries. Rosales and Stallone found that the newspaper crash reports described crashes better than individual or vehicle behaviour. ${ }^{8}$ According to Voight et al, important safety messages were rarely reported; only $9 \%$ of crash reports mentioned seatbelts. ${ }^{9}$ Connor and Wesolowski commented that papers often presented crashes as dramas with a 'victim/villain' storyline, assigning blame in $90 \%$ and underreporting restraint use. $^{3}$ Similar findings were noted for reporting on farm injuries and residential fires. ${ }^{9-11}$ All of these studies identified the press as an important source of injury information, but with deficiencies. There was consensus on the need for better dialogue between public health advocates and the press, which our study has also shown. Our study also suggests that road safety advocacy will be more effective if advocates and public health spokespersons explicitly cultivate relationships with media professionals, and seek opportunities to proactively influence media reporting.

There are a number of limitations to this study. We analysed articles from four newspapers which have large national daily circulation, including both state-owned public newspapers, but did not include 33 additional privately owned newspapers in Ghana. We were not able to examine trends in reporting over time. Finally, we are not able to measure the impact of injury journalism on public and private behaviours.

\section{Box 1 Recommendations on strengthening injury prevention in the press}

- National media commissions can partner with public health and transportation safety organisations to provide short courses on evidence-based injury prevention strategies for journalists

- Schools of journalism can incorporate a course on road safety reporting in their curriculum, not only to review injury prevention but also to address one of the leading causes of fatal injury for journalists

- Editors can set standards for injury reporting, including regular identification of seatbelt use, alcohol involvement by drivers as well as pedestrians, and consideration of environmental risks

- Law enforcement officers can strengthen public education on traffic regulations and foster closer relationship with the media by regularly briefing them on crashes, arrests, and judicial judgements

- Transportation safety organisations could provide regular data to journalists, identifying high-risk pedestrian zones, and identifying preventable risk factors 


\section{What is already known on the subject}

The press can play an important role in promoting injury prevention and road safety.

- Opportunities to strengthen the role of the media in injury prevention have not been well addressed in low- and middleincome countries.

\section{What this study adds}

- This is the first study to address the role of the media in injury prevention in a low- or middle-income country.

- The press is already playing an important role in promoting road safety in Ghana, with detailed reporting of crashes and with appropriate recommendations for private sector and governmental actions in editorials, informational pieces, and commentaries.

- Editors may wish to consider how to improve coverage of pedestrian injuries, which constitute a significant proportion of road traffic injuries in Ghana, but a smaller proportion of existing reporting.

- Likewise, more coverage of recommended actions could be built into reports of crashes and pedestrian injuries, with greater focus on specific, effective safety measures such as seatbelt use and speed control measures.

In conclusion, this study highlighted that the Ghanaian press can play an important role in promoting safety and injury control. Increasing the media's role in injury prevention could be accomplished by improving dialogue between public health and media practitioners, as well as by considering specific measures (see box 1).

Funding This study was funded, in part, by a grant (D43-TW007267) from the Fogarty International Center, US National Institutes of Health and by a grant (R49 CE000197) from the US Centers for Disease Control and Prevention.

\section{Competing interests None.}

Contributors IKY, BE, CM, and RO conceived the study design. IKY gathered and analysed the data and wrote the first draft of the paper. GEA was the second observer. All co-authors provided input to the study design and data analysis, read the paper, revised it critically for important intellectual content, and gave their final approval for the version to be published. The guarantor for the paper is IKY.

Provenance and peer review Not commissioned; externally peer reviewed.

\section{REFERENCES}

1. Peden M, Scurfield R, Sleet D, et al. World report on road traffic injury prevention. Geneva: World Health Organization, 2004.

2. Rahman F, Andersson R, Svanstrom L. Potential of using existing injury information for injury surveillance at the local level in developing countries. Public Health 2000:114:133-6.

3. Connor S, Wesolowski K. Newspaper framing of fatal motor crashes in four Midwestern cities in the United States, 1999-2000. Injury Prevention 2004; 10:149-53

4. Pan Z, Kosicki G. Framing as strategic action. In: Reese S, Gandy 0, Grant A, eds Framing public life: perspectives on the media and our understanding of the social world. Mahwah, NJ: Lawrence Erlbaum Associates, 2001.

5. World Bank. Country classification: classification of economies. Washington, DC, The World Bank Group, 2009. http://www.worldbank.org/data/countryclass/ countryclass.html (accessed 6 May 2009).

6. Odero W, Garner P, Zwi A. Road traffic injuries in developing countries: a comprehensive review of epidemiologic studies. Trop Med Int Health 1997:2:445-60.

7. National Road Safety Commission. Annual Report 2007. Accra: National Road Safety Commission of Ghana, 2007.

8. Rosales M, Stallones L. Coverage of motor vehicle crashes with injuries in U.S. newspapers, 1999-2002. J Safety Res 2008;39:477-82.

9. Voight B, Lapidus G, Zavoski R, et al. Injury reporting in Connecticut newspapers. Injury Prevention 1998:4:292-4.

10. Clegg-Smith K, Cho J, Gielen A, et al. Newspaper coverage of residential fires: an opportunity for prevention communication. Injury Prevention 2007;13:110-14.

11. Lundalv J. Farm-related injury event, social consequences and injury reporting in the Land Lantbruk newspaper in Sweden. Aust J Rural Health 2006:14:249-52. 